\title{
'Pucker Sign' an indicator of irreducible knee dislocation
}

\author{
Santosh Somayya Jeevannavar, Chidendra Manohar Shettar
}

Department of Orthopaedics, SDM College of Medical Sciences and Hospital, Dharwad, Karnataka, India

\section{Correspondence to}

Dr Santosh Somayya

Jeevannavar,

drssj99@gmail.com

\section{DESCRIPTION}

A 32-year-old policeman presented to the emergency department with acute right knee pain and swelling after a fall. The injury was sustained while playing kabbadi (an Indian game) as a result of a twisting injury to the knee. He was initially treated at a local hospital where they diagnosed it as a knee dislocation. However, he was referred to our institution after an unsuccessful attempt at closed reduction. On clinical evaluation, the patient was haemodynamically stable and all vital parameters were within normal limits. Clinical examination of

(a)

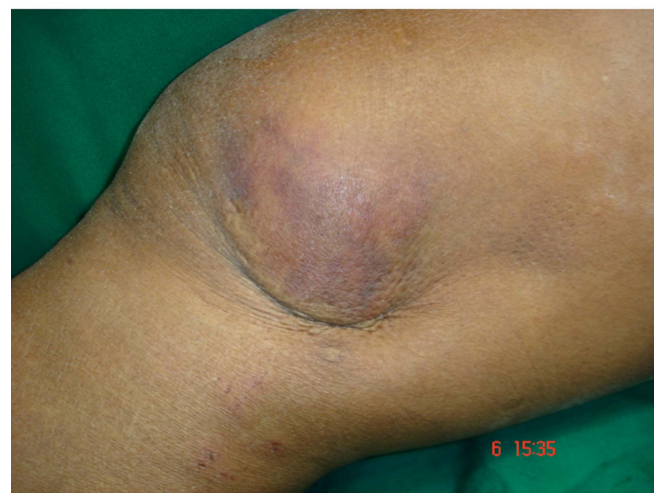

Figure 1 ( $A$ and B) Clinical photograph showing the medial aspect of right knee joint. The medial femoral condyle has button holed through the medial capsuloligamentous structures and lies subcutaneously. We can also see the skin and medial subcutaneous tissues being entrapped between the medial femoral condyle and the joint cavity producing the 'pucker sign'. (a)

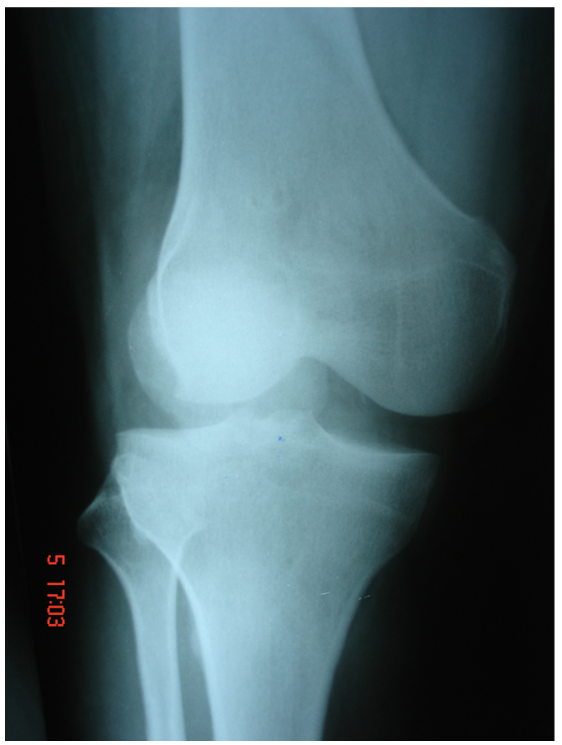

(b)

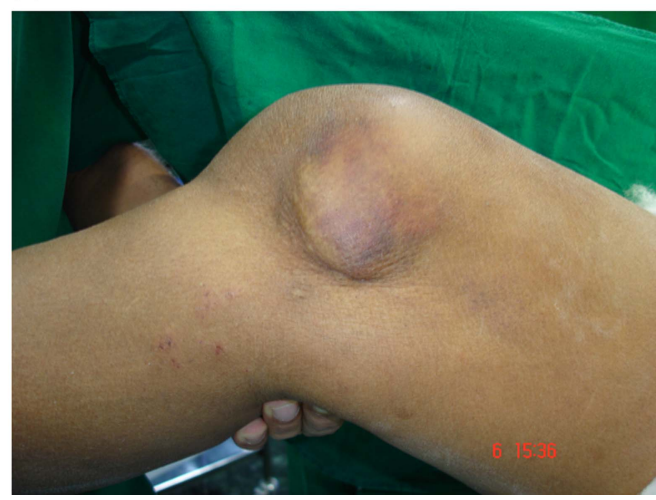

the right knee revealed a painful and mildly swollen right knee with 'puckering' of the skin overlying the medial femoral condyle (figure 1A,B). It appeared as though the skin overlying the medial femoral condyle was trapped inside the knee joint.

Range of movement of the right knee was painful and limited. Clinical evaluation for ligamentous instability could not be performed due to pain. A thorough clinical evaluation for neurovascular compromise (Doppler and CT angiogram) was found to be negative. Radiological investigations (X-rays (figure 2) and MRI (figure 3A,B))

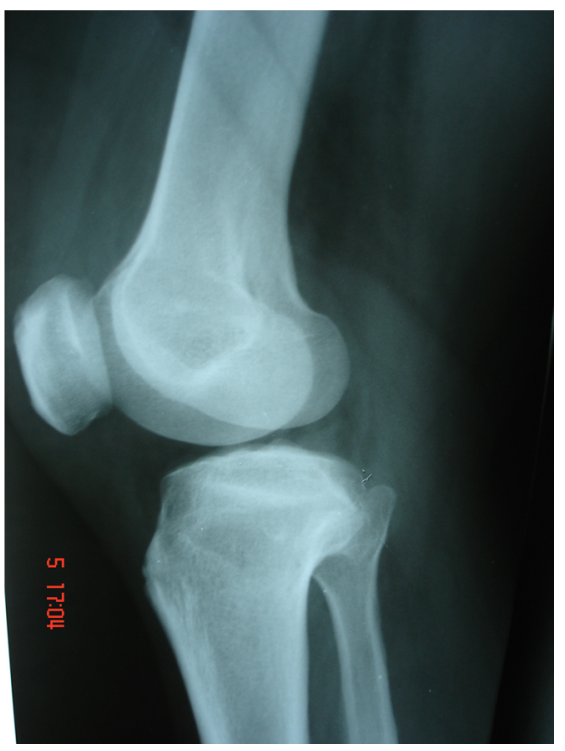

Figure 2 (A and B) Anteroposterior and lateral X-rays of the right knee showing posterolateral subluxation. 
(a)

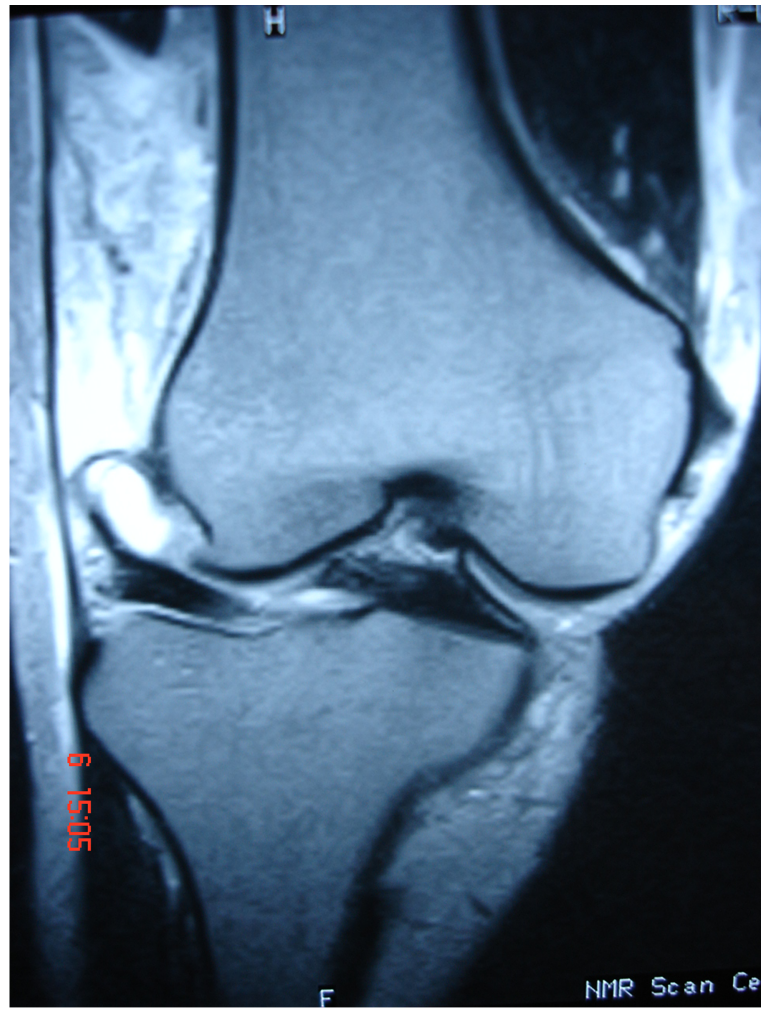

(b)

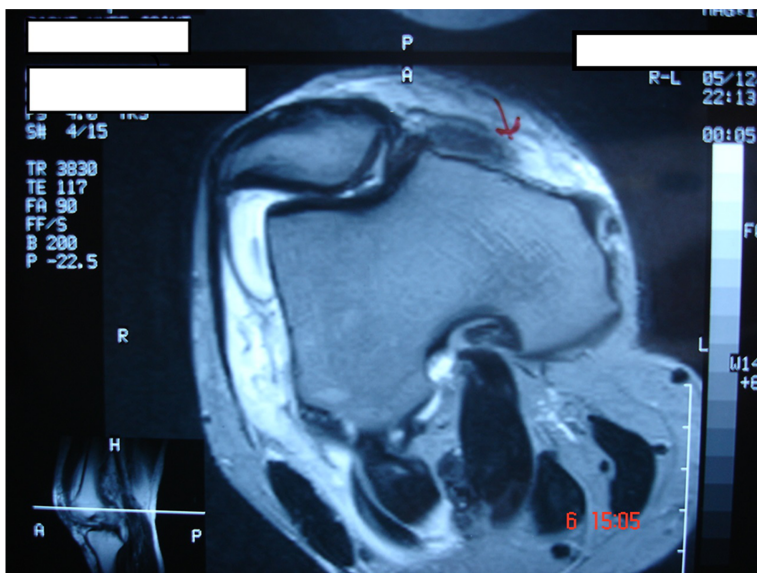

Figure 3 ( $A$ and $B$ ) MRI pictures of the right knee coronal and axial view demonstrating the buttonholing of the medial femoral condyle and entrapment of the medial capsuloligamentous structures in the medial joint cavity. There is mid-substance tear of the medial collateral ligament.

were suggestive of posterolateral knee dislocation with button holing of medial femoral condyle. There was a midsubstance tear of medial collateral ligament (MCL) and medial retinaculum with the torn structures interposed in the medial joint cavity with a partial anterior cruciate ligament (ACL) tear.

The patient underwent emergency open reduction through the anteromedial approach where the interposed medial structures were dissected out and the medial femoral condyle reduced. Midsubstance MCL tear was repaired along with the medial structures (figures 4-6). No attempt was made to repair or reconstruct the partially torn ACL. Once the wounds healed patient was mobilised in a knee brace and followed up regularly. There was no breakdown of the skin wound. The patient was

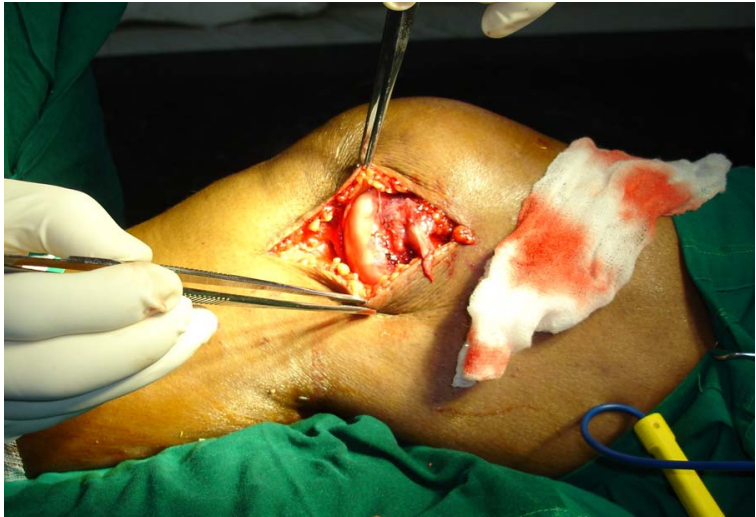

Figure 4 Intraoperative photograph demonstrating the midsubstance medial collateral ligament tear and the buttonholed medial femoral condyle.

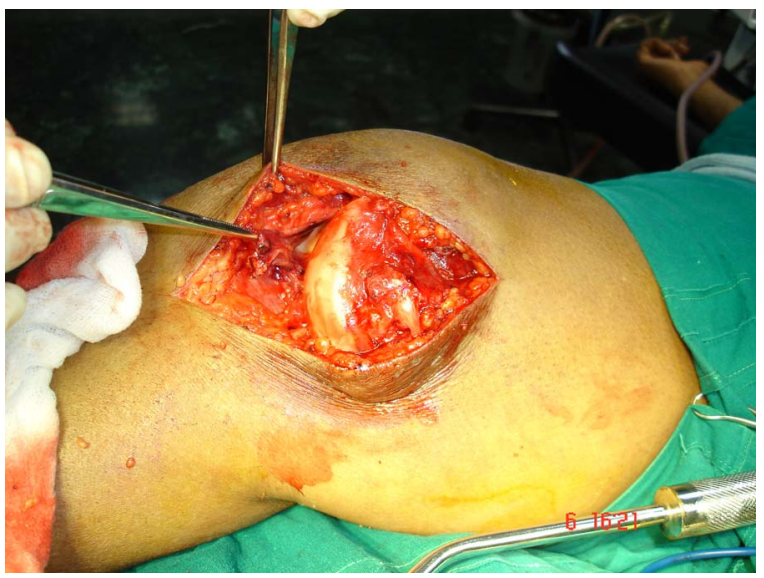

Figure 5 The torn medial structures blocking the reduction of the medial femoral condyle can be observed entrapped in the joint cavity.

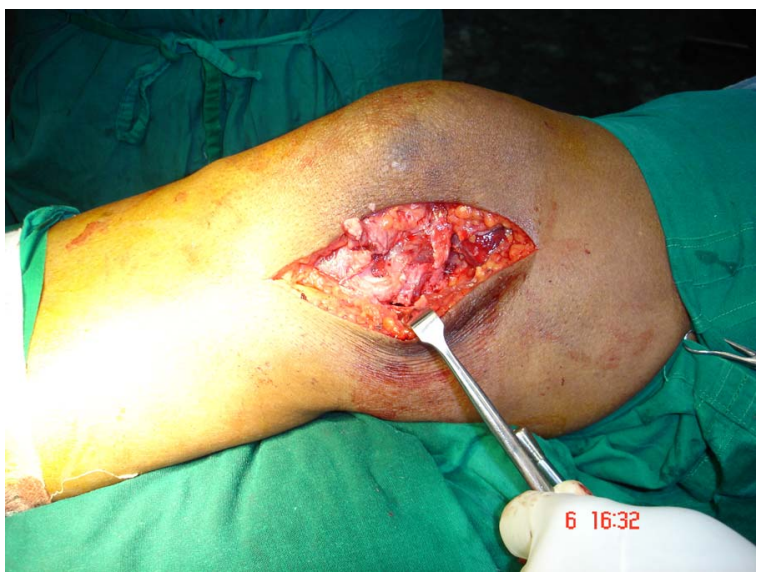

Figure 6 Intraoperative photograph after completion of the reduction and repair of the torn medial collateral ligament. 


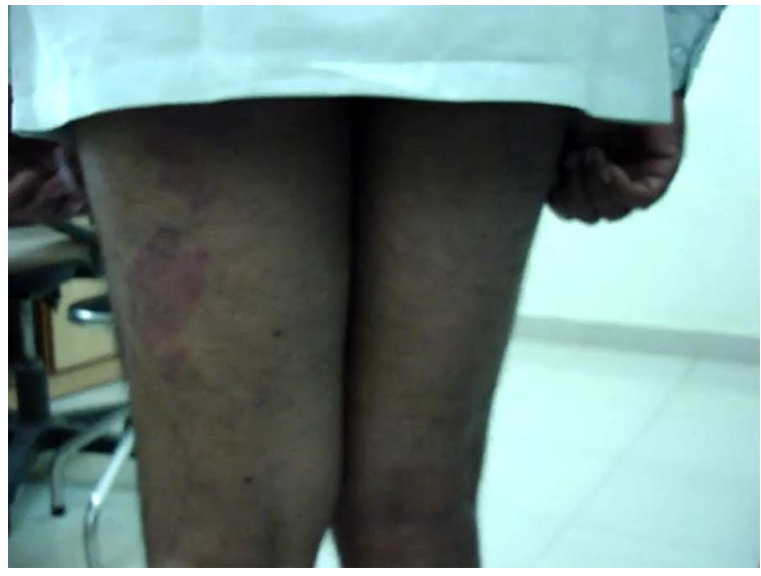

Video 1 video demonstrating functional movements of right knee at 5 years follow up with no ligamentous instability and pain.

\section{Learning points}

- Irreducible dislocation of knee joint or posterolateral dislocation of knee joint is a rare but well-documented entity which should be kept in mind while evaluating knee injuries in the emergency department.

- 'Pucker sign' or 'dimple sign' is an important physical sign denoting irreducibility and possible neurovascular compromise.

- Prompt open reduction and ligamentous repair is the treatment of choice.

- Delay in diagnosis or missed diagnosis can result in skin necrosis. followed up regularly for any knee pain and instability. At 6 years follow-up the patient had a stable, pain free knee with full range of movement (video 1).

Irreducible dislocation of knee joint or posterolateral dislocation of knee joint is a rare but well-documented entity. ${ }^{1-5}$ The mechanism of injury is violent abduction and external rotation of the knee. It is important to recognise and treat this condition promptly as it is not reducible by closed methods.

'Pucker sign' or 'dimple sign' is an important physical sign denoting irreducibility and need for prompt open reduction. Delay in diagnosis and treatment can result in skin necrosis. ${ }^{6} 7$

Contributors All the authors contributed in preparation and were involved in the treatment of the patient.

Competing interests None.

Patient consent Obtained.

Provenance and peer review Not commissioned; externally peer reviewed.

\section{REFERENCES}

1 Quinlan AG, Sharrard WJW. Posterolateral dislocation of the knee with capsular interposition. J Bone Joint Surg [Br] 1958;40B:660-4

2 Brennan JJ, Krause ME, MacDonald WF. Irreducible posterolateral dislocation of the knee with grossly intact cruciate ligaments. Am J Surg 1962;104:117-20.

3 Nystrom M, Samimi S, Ha'eri GB. Two cases of irreducible knee dislocation occurring simultaneously in two patients and a Review of the literature. Clin Orthop 1992;277:197-200.

4 Wand JS. A physical sign denoting irreducibility of a dislocated knee. J Bone Joint Surg [Br] 1989;71:862.

5 Tsiagadigui JG, Sabri F, Sintzoff $S$, et al. Magnetic resonance imaging for irreducible posterolateral knee dislocation. J Orthop Trauma 1997;457-60.

6 Hill JA, Rana JA. Complications of posterolateral dislocation of the knee: case report and literature review. Clin Orthop Relat Res 1981;154:212-15.

7 Joseph Abate MD. Dislocations and soft tissue injuries of knee. In: Browner BD, Jupiter JB, Levine AM, Trafton PG, Krettek C. eds. Skeletal trauma: basic science, management and reconstruction. 4th edn. Philadelphia, USA: WB Saunders, 2008:2167-72.

Copyright 2013 BMJ Publishing Group. All rights reserved. For permission to reuse any of this content visit http://group.bmj.com/group/rights-licensing/permissions.

BMJ Case Report Fellows may re-use this article for personal use and teaching without any further permission.

Become a Fellow of BMJ Case Reports today and you can:

- Submit as many cases as you like

- Enjoy fast sympathetic peer review and rapid publication of accepted articles

- Access all the published articles

- Re-use any of the published material for personal use and teaching without further permission

For information on Institutional Fellowships contact consortiasales@bmjgroup.com

Visit casereports.bmj.com for more articles like this and to become a Fellow 